\title{
Efficiency of communicating personality impressions as a function of coding context
}

\section{J. EDWIN BOYD, The University of Calgary, Calgary, Alta., Canada}

Twenty Ss briefly characterized or coded their impressions of each of 10 hypothetical people. Ten Ss coded each person while having available the other nine person-descriptions; $10 \mathrm{Ss}$ coded each person independently of the other persondescriptions. Messages were decoded by two groups of $10 \mathrm{Ss}$ who identified the intended person in each message. Message length and identification errors were recorded. Impressions coded in context were transmitted more efficiently than those coded independently. Message length and errors were negatively correlated for the context groups only. Implications for further studies were discussed.

Information theory (e.g., Frick, 1959) has been concerned with communication systems where information is transmitted by components which operate according to strict logical rules. The assumptions of this model can be met by sources and destinations incorporating the characteristics of computer input and output devices. These assumptions are not entirely applicable to systems where the source and/or destination of messages makes inferences beyond the logical requirement of message content. Verbal communication between people does not usually follow the same logical rules as, for example, computer input and output devices do. Consequently, relationships between variables derived from a formal system may not be reflected in the human communication situation. Maclay (1962) suggested an analysis of human communication to identify and measure the relevant variables and the rules by which they combine to achieve information transmission. The system is confined to examining encoding and decoding of messages.

Coding is the process of assigning an explicit symbol or label to a referent, concept or experience. Brown (1965) and Brown \& Lenneberg (1956) have shown that cultural differences exist with regard to the categorization and consequent labelling of certain perceptual experiences. Lantz (1963) experimentally demonstrated the process of encoding and decoding a set of 20 Munsell color chips. One group of Ss chose labels to denote each chip; another group used these labels to try to identify the intended chips. A color with a high codability score was one that the first group of Ss generally transmitted accurately to the second group. In a similar experiment using geometric shapes as stimuli Maclay \& Newman (1960) examined the effects of feedback conditions (positive, negative, and zero) and the nature of the array of stimuli (homogeneous vs heterogeneous shapes) on message length. These authors indicated that differences in message length attributable to differences between ranges of stimulus arrays may be related to the codability of each stimulus in the array.

The assumption on which the present study is based is that communication about impressions of people can be similarly studied as is communication about arrays of inanimate objects. The study examines the effects of the presence or absence of a context array of person descriptions during encoding on the efficiency of transmitting impressions of people. Efficiency is a function of both message length and decoding accuracy (Maclay, 1962). It can be inferred that presence or absence of an array of referents affects efficiency since the array is hypothesized to influence both message length and accuracy through its influence on codability. The hypothesis to be tested can be stated as follows: Impressions of people coded with reference to an array of people are transmitted more efficiently than impressions coded independently of the array. SUBJECTS

The Ss were 40 volunteers from introductory psychology classes and randomly assigned to one of four groups.

\section{MATERIALS AND PROCEDURES}

Ten hypothetical people comprising the context array wert each represented by a person-description typed on a $5 \times 8$ in. card. The descriptions were drawn from earlier studies by Boyd \& Jackson (1967) and Jackson (1966) and included the behavioral information characteristic of each person.

Encoders were shown the person descriptions and informed that each one was an "interview summary" written by an expert who had interviewed the person several times. Each encoder was then instructed to write down a descriptive word or phrase so that a person reading their description could recognize which person the $S$ intended to denote.

Ten encoders received all 10 descriptions at once and were encouraged to sort through the cards before writing their descriptions. This procedure provided a context within which each hypothetical person was encoded. Ten other encoders were given the description cards singly, a different random order being used for each S. Each impression was thus encoded independently of the context array. Encoding time for both groups was equated.

Messages generated by encoders in the context and no-context groups were compiled in booklets. Each booklet contained 20 messages, two intended to depict each of the 10 hypothetical people.

Two groups of 10 decoders each were presented with the message booklets and the 10 cards containing the person descriptions. One group of decoders received only messages coded in context while the other group received only messages coded out of context. They were informed about the prior encoding task and asked to decode each message by writing down the name of the person they thought was described in the message. Decoders could choose one name several times if they wished and omit others altogether.

The two measures used were mean number of words per encoded message and number of error choices in decoding.

\section{RESULTS AND DISCUSSION}

The mean of 4.34 words-per-message used by encoders under the context condition was significantly smaller than the mean of 6.75 words-per-message used by $S$ s under the no-context condition $(\mathrm{t}=5.4, \mathrm{p}<.001)$. The difference between the mean number of errors in decoding each type of message was not significant. The coding efficiency of the two groups was thus different, the context group being more efficient (see Table 1).

To assess the relationship of message length to accuracy within each group, a rank order correlation between mean number of words-per-message and total number of identification errors generated by these messages was calculated. For the

Table 1

Summary of Measures for Encoding and Decoding Variables Under Two Coding Conditions

\begin{tabular}{lcc}
\hline Measures & \multicolumn{1}{c}{ Coding Conditions } \\
\cline { 2 - 3 } Mean No. of Words & Context & No Context \\
Mean No. of Errors & 4.34 & 6.76 \\
Word-Error Correlation & 6.10 & 6.00 \\
\hline
\end{tabular}


context condition, tho was $-.58(\mathrm{p}<.05)$; for the no-context condition, rho was -.25 (n.s.). Longer messages were accompanied by a decrease in error choices when impressions were coded in context. The relationship was not significant when impressions were coded independently of context.

The results supported the hypothesis that impressions of people coded with reference to an array of people are transmitted more efficiently than impressions coded independently of the array. Significantly fewer words-per-message coded in context generated a similar number of identification errors as did longer messages coded out of context resulting in greater transmission efficiency for context encoders.

The rank order correlations between message length and errors in each group suggest the reasons for this difference. The context coders were able to encode the characteristics which most easily differentiated each person. This comparison process permitted encoders to use only those words necessary to depict their impressions. When longer messages were generated they tended to result in fewer decoding errors so that efficiency did not decrease. Subjects in the no-context condition were unable to encode the most distinctive features of each person since they lacked a basis of comparison of one person with another. These encoders resorted to longer messages, the extra words being irrelevant for accurate decoding since length and errors were not related. Increased length without decreased errors resulted in lowered efficiency.

The application of a communication paradigm to studies of person perception seems quite apparent. Advantages of this approach are implied by Maclay \& Newman (1960) who suggest that motivational variables, personality characteristics of communicators, and sociocultural variables may influence the nature of communication. Schroder, Driver, \& Streufert (1967) indicate that interactions between environmental and personality variables in communication is the rule rather than

\section{Continued from page 56$)$}

dimension took less time to learn the initial discrimination than did Ss trained in their nonpreferred dimension.

There was no treatment effect on the choice to reverse or nonreverse. Ss reversed just as frequently when trained in the nonpreferred dimension. Seven Ss trained in their preferred dimension chose to reverse as did seven Ss trained in their nonpreferred dimension.

A further analysis which divided Ss into four groups, Reversers (Preferred and Nonpreferred) and Nonreversers (Preferred and Nonpreferred), yielded Mean trials and SDs of $2.42(5.18), 29.57$ (17.39), 12.71 (13.37), and 13.77 (14.35), respectively. Bartlett's test for homogeneity of variance yielded positive results and for this reason, a square root transformation of the scores was made. An analysis of variance indicated an effect of preference $(\mathrm{F}=7.53, \mathrm{df}=1 / 24$, $p<.025)$ and an interaction effect $(F=6.14, \mathrm{df}=1 / 24$, $\mathrm{p}<.025)$. Fig. 1 graphs these data. This analysis revealed that the effect of preference was due to the performance of those Ss who reversed.

\section{DISCUSSION}

The results of this study supported the hypothesis that dimensional preference has an effect on discrimination learning. This has been reported a number of times (O'Brien, 1966; Smiley \& Weir, 1967; Suchman \& Trabasso (1966); and Wolff, 1966).

The data, however, do not support the hypothesis that Ss trained in their preferred dimension will more likely exercise the reversal option. Furthermore, it was found that dimensional preference affected original learning only for those Ss who subsequently chose to reverse. These results are difficult to explain in terms of attention theory. It would seem, according to that viewpoint, that the group trained in their preferred dimension would show more rapid initial learning and a greater proportion of reversers. Attention theory would have particular difficulty in accounting for the the exception. Communicating about impressions of people seems to be a natural and ubiquitous process. Consequently, the more reliable and objective measures from communication research might be brought to bear on studies of impression formation as revealed in message characteristics to provide increased understanding of social perception phenomena.

\section{REFERENCES}

BOYD, J. E., \& JACKSON, D. N. The perceived structure of social attitudes and personality: A multidimensional scaling approach. Multivariate Behavioral Research, 1967, 2, 281-297.

BROWN, R. W. Social psychology. New York: The Free Press, 1965.

BROWN, R. W., \& LENNEBERG, E. H. A study in language and cognition. Journal of Abnormal \& Social Psychology, 1954, 49, 454-462.

CARROLL; J. B., \& CASAGRANDE, J. B. The function of language classifications in behavior. In E. E. Maccoby, T. M. Newcomb, and E. L. Hartley (Eds.), Readings in social psychology. New York: Holt, 1958. Pp.18-31.

FRICK, F. C. Information theory. In S. Koch (Ed.), Psychology: A study of a science. Vol. 2. General systematic formulations, learning, and special processes. New York: McGraw-Hill, 1959. Pp. 611-636.

JACKSON, D. N. A modern strategy for personality assessment: The Personality Research Form. Paper read at American Psychological Association, New York, September, 1966.

LANTZ, D. L. Color naming and color recognition: a study in the psychology of language. Unpublished doctoral dissertation, Harvard University, 1963.

MACLAY, H. A descriptive approach to communication. In N. F, Washburne (Ed.), Decisions, values, and groups. Vol. 2. New York: Pergamon Press, 1962. Pp. 201-226.

MACLAY, H., \& NEWMAN, $S$. Two variables affecting the message in communication. In D. Willner (Ed.), Decisions, values, and groups. Vol. 1. New York: Pergamon Press, 1960. Pp. 218-228.

SCHRODER, H. M., DRIVER, M. J., \& STREUFERT, S. Human information processing. New York: Holt, Rinehart, \& Winston, 1967. NOTE

1. This work was supported in part by grants from the Alcoholism and Drug Addiction Research Foundation of Ontario, and by the Canada Council.

pertorman

pertormance of Ss trained on the nonpreferred dimension. Amo showed the greatest difficulty in original learning were more likely to elect the reversal option.

Although these data are by no means conclusive, they can be taken in support of a theory such as the Kendlers', which emphasizes stages of development and the existence of a transition period when mediational processes, in addition to attentional biases, begin to influence the performance of children in discrimination learning tasks.

\section{REFERENCES}

KENDLER, H. H., \& KENDLER, T. S. Vertical and horizontal processes in problem solving. Psychological Review, 1962, 69, 1-15.

KENDLER, H. H., KENDLER, T. S., \& LEANARD, B. Mediated responses to size and brightness as a function of age. American Journal of Psychology, 1962, 75, 571-586.

O'BRIEN, T. Dimensional preference effect on reversal shifts of first and second graders. Unpublished Master's Thesis, St. Louis University, 1966.

SMILEY, S., \& WEIR, M. W. The role of dimensional dominance in reversal and nonreversal shift behavior. Journal of Experimental Child Psychology, 1967, 5, 296-307.

SUCHMAN, R., \& TRABASSO, T. Stimulus preference and cue function in young children's concept attainment. Journal of Experimental Child Psychology, 1966, 3, 188-198.

WOLFF, $J$. The role of dimensional preferences in discrimination learning. Psychonomic Science, 1966, 5, 555-556.

ZEAMAN, D., \& HOUSE, B. The role of attention in retardate discrimination learning. In N. R. Ellis (Ed.), Handbook of mental deficiency. New York: McGraw-Hill, 1963. NOTE

1. This study is based primarily on a thesis submitted by the first author, now Lynn McLaughlin, to the Graduate School, St. Louis University, in partial fulfillment of the requirements for the Master of Science Degree. 